\title{
O PODER DE FOUCAULT NA SALA DE AULA: ALUNOS ALgOZES E PROFESSORES VITI MADOS?
}

Clarissa Menezes Jordão, UFPR

Laura Amato, UFPR

RESUMO: este texto aborda os conceitos de poder e saber de Foucault num espaço formal de formação de professores - um grupo de estudos. Apontamos semelhanças e diferenças entre este contexto e o das salas de aula em geral, enfocando as relações de poder que se estabelecem entre os participantes destes contextos, em especial em relação ao estatuto social do conhecimento em cada espaço. Ressaltamos o aspecto produtivo do poder no pensamento de Foucault, especialmente na multiplicidade de determinações que caracteriza a sala de aula de língua estrangeira.

PALAVRAS-CHAVE: poder, saber, língua estrangeira, formação, resistência

Todo sistema de educação é uma maneira política de manter ou de modificar a apropriação dos discursos, com os saberes e os poderes que eles trazem consigo.

Foucault, 2005b, p. 43-44

A citação acima é proveniente de uma das obras discutidas no grupo de estudos "Identidade e Leitura" da UFPR. O grupo escolhe autores para estudo tendo como base sua eventual relação com questões educacionais na sociedade atual, priorizando aqueles que vêem a língua numa concepção discursiva, o conhecimento como parcial e contingente e as interações entre sujeitos e saberes como sempre permeadas pela capilaridade do poder. Escolher Foucault não foi uma tarefa fácil, pois embora seu pensamento se enquadre nestes critérios, ele não trata diretamente de educação em suas obras, como fazem Freire e Sterling, por exemplo, mas foi através da sua episteme que o grupo discutiu as relações sociais existentes no mundo e a função da escola na sociedade.

Devido às discussões realizadas, as vozes individuais se perderam dentro do grupo, pois não sabemos mais o que é de cada um e por isso este texto não é de um indivíduo, mas de todos, uma vez que vem assumidamente permeado das vozes do grupo, dos colegas de trabalho, das nossas experiências de vida e da nossa vivência como leitoras. Não podemos dizer que o texto é de autoria única, mas sim feito a partir de interpretações dos pontos de vistas apresentados nas discussões em grupo. Entretanto, duas de nós se responsabilizam por assinar aquilo que os leitores costumam entender como os "sentidos do texto" mas que, de acordo com nossas leituras de Foucault, 
entendemos como sentidos que o leitor atribuirá ao texto com base em suas experiências de leitura, suas visões de mundo, sua ideologia enfim. Restringimos a função-autor deste texto a dois nomes no grupo, por força das circunstâncias - locais e globais - que exigem alguém a quem responsabilizar pelos sentidos que venham a ser culturalmente atribuídos a ele no processo de interpretação do texto.

Dobrando-nos assim às convenções do mundo contemporâneo da escrita, vamos seguir tratando este texto como se contivesse em sua estrutura os sentidos que o leitor constrói com ele. Assim, vamos pressupor que ele traz alguns dos questionamentos levantados no grupo de pesquisa durante a leitura e discussão de textos de Foucault e de alguns dos seus comentaristas, discussões nas quais sempre pensávamos sobre os contextos de educação em língua estrangeira. Nossa intenção é problematizar principalmente a relação poder-saber na educação em geral e no ensino da língua estrangeira em particular, pensando a interação dos agentes na sala de aula e a função da língua estrangeira no contexto educacional local.

Ao abordar o contexto de leitura em que estes textos foucaultianos foram comentados, ou seja, o contexto de existência do grupo de pesquisa Identidade e Leitura, observamos uma questão importante a ser destacada quando se tratam de relações de poder e agência. O grupo é composto majoritariamente por professores de língua inglesa, com uma única professora de alemão. Durante nossas discussões sempre falamos de como era vista tal questão na perspectiva $X$ ou $Y$, e sempre tínhamos a visão da professora de alemão como uma perspectiva diferente, marginal. Outro tema que aparecia era a "língua" utilizada no grupo. Todas nós temos o português como língua materna e lemos em inglês, sendo assim, líamos nessas duas línguas, e deixávamos de fora, inconsciente ou até conscientemente, outras perspectivas, escritas por outros autores em outras línguas. Talvez, mesmo sem ter feito uma opção explícita por isso, valorizamos uma única língua estrangeira, colocando-a como central e dominante. Assim, as outras línguas, e conseqüentemente outras perspectivas, foram ignoradas ou subvalorizadas. E isso num grupo que trata de questões de identidade, discurso e poder. A preferência por uma determinada perspectiva/ língua e a suposta necessidade de optarmos por aquelas perspectivas/línguas que conhecemos pode ser um indicativo da dificuldade que temos em nos desacomodar, em nos permitir a instabilidade diante do novo - a escolha pela língua inglesa foi entendida pelo grupo como "natural", não sendo questionada nem mesmo pela participante de língua alemã, numa demonstração clara do caráter dominador de certas formas de ver o mundo.

Apesar de todos tentarem se observar como iguais, evidentemente nos nossos discursos se reconheciam diferentes posições de poder que nos remetiam ao ambiente de uma sala de aula - alguns de nós se colocando no grupo em função de sua experiência 
profissional ou acadêmica, outros em função de suas capacidades de explicação e argumentação, outras trazendo um maior lastro de leituras, mas todas reforçando a posição de que era necessário manter a estrutura do grupo com uma liderança, responsável tácita pela "palavra final". Outra questão interessante sobre as identidades que assumíamos foi a relação explícita com a "sala de aula" nas discussões que fazíamos nas reuniões do grupo: por ato falho, várias vezes usávamos expressões como "na aula seguinte" ou "na aula anterior", remetendo à estrutura de ensino/aprendizagem formal de uma sala de aula tradicional. O desequilíbrio das posições de poder era perceptível também nas falas dos membros, pois sempre havia alguém que falava mais, tinha a última palavra e era mais "respeitado".

Então, recorremos a Foucault para entender o percurso do grupo. As relações entre as línguas materna e estrangeiras, bem como as relações entre os membros do grupo estão permeadas de poder. Afinal, "o poder não é fonte nem origem do discurso. O poder é alguma coisa que opera através do discurso, já que o próprio discurso é um elemento em um dispositivo estratégico de relações de poder" (Foucault, 2006, p. 253). Vemos nas situações destacas acima a manifestação do poder no discurso; vemos que o poder simplesmente 'is' (é e está ao mesmo tempo), ou seja, ele se faz presente a todo o momento.

Geralmente relacionamos a idéia de poder opressor a um Estado autoritário, mas para Foucault o poder faz parte das relações humanas e das instituições, independentemente da relação política estabelecida. Saber que as relações humanas e as instituições, que são constituídas pelas relações humanas, são formadas pelo poder, nos ajuda a entender os papéis sociais que atravessam os indivíduos. Pensar em poder na perspectiva de Foucault significa perceber que se sentir oprimido supõe que alguém esteja ocupando a posição de opressor; supõe também que exista uma repressão e com isso necessariamente ocorra algum tipo de resistência. Mas Foucault parece explicar isso melhor, quando escreve:

A partir do momento em que há uma relação de poder, há uma possibilidade de resistência. Jamais somos aprisionados pelo poder: podemos sempre modificar sua dominação em condições determinadas e segundo uma estratégia precisa. (Foucault, 2005a, p. 241).

Essas palavras nos levam a refletir sobre as relações que acontecem na sala de aula (mesmo sem levar em conta o contexto educacional maior) entre professor e aluno e entre os alunos. Em nossa cultura escolar o professor ainda é o 'dono do saber' e 'deve' estar à frente dos seus alunos para transmitir o 'conhecimento', nos moldes da educação "bancária" de que nos falou Freire, na qual o "educador é o sujeito, [que] conduz os 
educandos à memorização mecânica do conteúdo narrado" (Freire, 2004, p. 58). O professor se percebe em posição de poder ao representar-se como hierarquicamente superior a seus alunos, tanto institucionalmente quanto em termos de conhecimento e/ou experiência adquiridos, devendo então ser respeitado pelos alunos por isso. Freire afirma também que nessa perspectiva "o 'saber' é uma doação dos que se julgam sábios aos que julgam nada saber" (2004, p. 58), e parte daí para analisar as situações de poder na escola, principalmente ao citar a relação entre opressor e oprimido, na qual o objetivo do opressor "é transformar a mentalidade dos oprimidos e não a situação que os oprime" (ibid., p. 60). Nessa mesma relação, o aluno (oprimido) deve escutar o professor (opressor) e segui-lo, numa cultura escolar discipular; o aluno deve então reconhecer o poder do professor e ser disciplinado pela instituição escolar (cf. Foucault, 2005c). Pensando assim, os alunos deveriam idealmente manter-se em silêncio absoluto e a escola transformar-se num lugar de obediência e meditação. Gore (1994) explica que há semelhanças entre a pedagogia escolar e a técnicas de governo: para ela, em ambos há formas particulares de autoregulamento e autocontrole que agem para disciplinar os corpos, a fala e os movimentos.

Mas, felizmente, essa prática de inculcação de autodisciplina nem sempre é bem sucedida; na verdade, parece que a sala de aula é o ponto absoluto da resistência à imposição de poder, uma vez que constantemente temos que lidar com reações dos alunos que não são reconhecidas pelos professores como "aceitáveis", causando nos professores uma sensação de impotência e incompetência. Diante das atitudes de resistência dos alunos, os professores costumam representar-se como 'vítimas' e não se sentem respeitados como as autoridades que acreditam ser, desistindo de engajar-se com os alunos e suas estratégias, defendendo-se de questionar a instituição e suas práticas, escondendo-se por trás do discurso de que as 'gerações atuais não respeitam ninguém', e de que 'bons modos' não se adquirem na escola, eles 'vêm do berço'.

Essa sensação de impotência que leva ao desengajamento está muitas vezes ligada à falta de reconhecimento e valorização do trabalho docente na sociedade e na escola. Gore (1994, p.15) corrobora essa idéia dizendo que "se as relações de poder são dispersas e fragmentadas ao longo do campo social, assim também o deve ser a resistência ao poder". Se retomarmos a citação anterior de Foucault, veremos que tais reações fazem parte da oposição ao poder explícito e imposto, isto é, a reação dos alunos faz parte do jogo da relação professor-aluno, onde o poder primeiro, o do professor legitimado pela instituição -, é ameaçado pelo segundo poder, o do aluno, que reage com o papel institucional que tem, modificando o primeiro poder, fazendo com que o professor reaja e encontre voz (e conseqüentemente, poder) em outro grupo (geralmente no grupo de iguais). Essa relação faz parte de um círculo vicioso, no qual o 
poder é constantemente transferido e os participantes interagem conforme os contratos sociais (cf. Rousseau, 1993).

A relação aluno-aluno também não é sempre amigável. O desejo de poder faz parte de qualquer relação humana, isto é, a vontade de dominar através do poder/saber é uma prática constante em nossas interações. Um grupo de alunos muitas vezes se mantém contra um outro grupo ou um outro indivíduo, sendo esse, na maioria das vezes, o professor, mas também pode ser um colega mais fraco, mais gordo, mais inteligente, menos inteligente, mais alto, mais baixo, loiro, moreno, etc., somente por ser 'outro'. Para que ele seja marcado como diferente do grupo que está no 'poder' acontece um embate, que muitas vezes não é igualitário. Nesse ponto podemos (como professores) perceber na sala de aula a função do discurso como ferramenta estratégica de dominação, pois é através dele que se opera o poder do indivíduo ou do pequeno grupo frente ao(s) outro(s): a violência simbólica que o discurso institui e corporifica muitas vezes é mais impactante do que eventuais ações de violência física. Muitas vezes, nós professores observamos calados discussões entre alunos, como se estivéssemos numa aula de retórica da Grécia Antiga, onde os discípulos exercitavam seu poder de argumentação. Mas a disputa por poder ocorre tanto através de práticas de expressão corporal, de códigos e procedimentos de vestimenta ou do comportamento em sala e fora dela, quanto ocorre também nas discussões ou agressões verbais. Podemos caracterizar como discursivas todas essas práticas, e todas as práticas além destas, uma vez que discurso é o termo usado por Foucault para referir-se às práticas sociais de construção de sentidos, e que todas essas práticas sem dúvida constroem sentidos na sociedade.

Essas situações podem dar a entender que o poder é sempre dominador e restritivo. Entretanto, não é assim que nosso grupo (e vários outros leitores de Foucault, como Tomaz Tadeu da Silva ou Jennifer Gore, para citar dois exemplos) constrói no pensamento de Foucault. Ele diz que, ao falarmos de poder

o que vem à mente das pessoas é o exército, a polícia, a justiça. (...) Ora, quando se tem esta concepção do poder, penso que localizamos somente nos aparelhos de Estado, enquanto as relações de poder existem - mas isso sabe-se apesar de tudo, porém nem sempre se tiram as conseqüências -, passam por muitas coisas. As relações de poder existem entre um homem e uma mulher, entre aquele que sabe e aquele que não sabe, entre os pais e as crianças, na família. Na sociedade há milhares e milhares de relações de poder e, por conseguinte, relações de forças de pequenos enfrentamentos, microlutas, de algum modo. (Foucault, 2006, p. 231). 
Foucault nos apresenta essas microlutas como essenciais e normais, sem neutralidade, ou seja, elas ocorrem entre e dentro de um discurso ideológico e a partir desse embate são reconstruídas concepções, havendo trocas momentâneas ou permanentes da posição de poder. Nessas trocas, ser reconhecido como detentor de poder nem sempre é produtivo, uma vez que, ao ocupar espaços de poder, tendemos a nos solidificar nas posições de privilégio que vêm com tais espaços, e por isso tentamos manter o status quo da situação, já que é um status que nos beneficia. Por outro lado, estar em posição menos privilegiada nos apresenta a necessidade de resistir, de pensar como o outro, de buscar estratégias que nos permitam representar-nos e aos outros de maneira diversa, e quem sabe assim ocupar posições subalternas pode abrir nossa perspectiva, tornando-nos receptivos a embates e até a mudança de paradigmas (Spivak, 1988).

Para Foucault (2005b, p.133), “a 'verdade' está circularmente ligada a sistemas de poder, que a produzem e a apóiam, e a efeitos de poder que ela induz e que reproduzem". Estas 'verdades' produzidas fora da escola são difundidas no processo escolar e talvez aí esteja a grande função da educação: questionar e trabalhar com essas verdades pré-estabelecidas, não só para modificá-las, mas para entender como o poder é exercido e assim saber como as verdades são produzidas e difundidas. Nessa visão, o papel da educação vai além de transmissão os conhecimentos historicamente acumulados: ela precisa modificar os processos de apropriação e legitimação dos discursos, não se limitando à substituição de um discurso hegemônico por outro, mas promovendo a institucionalização da abertura do conhecimento escolar a novas propostas e perspectivas, trabalhando com as 'verdades' sociais como sendo sempre parciais, subjetivas e contingentes.

O ensino de uma língua estrangeira só faz corroborar a parcialidade dessas 'verdades', pois a partir da língua estrangeira podemos trabalhar diferentes visões, muitas vezes contrárias as da língua materna, já que o espaço escolar dedicado a este tipo de conhecimento é por excelência um espaço de contato com o 'outro', com a alteridade que nos constitui. A função da língua estrangeira na formação escolar está então, nesta perspectiva, em mostrar diferentes formas de 'verdades' e com isso relativizar as relações acima discutidas e apresentadas. A educação em língua estrangeira é responsável, também, pela manutenção ou discussão das perspectivas dominantes. Escolher uma língua estrangeira não é somente questão de gosto pessoal ou admiração pela cultura ou uma certa 'busca às origens'. Muitas vezes nos pautamos em critérios econômicos e sociais ao decidir quais línguas estrangeiras queremos aprender, isto é, decidimos dobrarmo-nos ou não às imposições do mercado econômico vigente, que transforma a língua em uma commodity com grande valor de compra e venda, na 
comercialização de cursos de idiomas e na exigência do domínio de um idioma para empregos no mercado de trabalho (J ordão, 2009).

Mas nem toda língua tem o mesmo valor em todos os locais: o inglês vale, no mundo globalizado de hoje, mais do que o guarani no Brasil do século XVI. Esse é um exemplo simples de como a valor das línguas variam conforme sua necessidade de uso e de difusão global ou local. Atualmente, acontece no Brasil uma mudança no 'mercado' das línguas estrangeiras com a obrigatoriedade de oferta do ensino da língua espanhola no currículo escolar. O Brasil pode ser considerado uma ilha da língua portuguesa no meio do mar de língua espanhola, sendo estranho não considerar a língua espanhola como sendo algo essencial para a comunicação com os vizinhos e possíveis parceiros políticos e comercias. O prestígio da língua espanhola no currículo atual se dá devido a uma mudança de prioridades do governo brasileiro, focando mais na América Latina e principalmente no Mercosul. Com o estreitamento das relações do Brasil no Mercosul, o espanhol se torna a mais nova commodity, mas não deixando de lado o inglês. Isso mostra que nossas escolhas não são arbitrárias e sim pautadas pelo poder, ao qual às vezes somos submetidos, mas também ao qual submetemos os outros; as nossas 'nãoescolhas' podem ser utilizadas para manter ou discutir as commodities utilizadas na educação.

Por isso, vamos encerrar a escrita deste texto de maneira aberta, admitindo compartilhar o poder dos sentidos construídos neste texto com nossos leitores, e na certeza de que no fundo sua escrita continua com as leituras que se venham a fazer deste texto. Encerramos assim com uma citação de Foucault, cujos sentidos possíveis procuraremos não determinar com nossos comentários explicativos que tradicionalmente seguem as citações em textos acadêmicos. Que nossos leitores se sintam à vontade para estabelecer as relações dela com nosso texto:

Sabe-se que a educação, embora seja, de direito, o instrumento graças ao qual todo indivíduo, em uma sociedade como a nossa, pode ter acesso a qualquer tipo de discurso, segue, em sua distribuição, no que permite e no que impede, as linhas que estão marcadas pela distância, pelas oposições e lutas sociais. (Foucault, 2005b, p. 43)

\section{Referencias bibliográficas}

FOUCAULT, M. Ditos e Escritos. Estratégia, Poder-saber. RJ: Ed. Forense Universitária, 2006. 
JORDÃO \& AMATO. 0 Poder de Foucault na Sala de Aula: alunos algozes e professores vitimados?

Revista X, vol.1, 2008.

Vigiar e Punir. Petrópolis: Ed. Vozes, 2005.c

Arqueologia do Saber. SP: Ed. Graal, 1982.

FREIRE, P. Pedagogia do Oprimido. Rio de Janeiro: Paz e Terra, 2004.

GORE, J. Foucault e Educação: Fascinantes Desafios. In: SILVA, Tomaz T. da. (Org.). 0 sujeito da educação: estudos foucaultianos. 2 ed. Petrópolis: Vozes, 1994.

JORDÃO, C. M. . English as a foreign language, globalisation and conceptual questioning. Globalisation, Societies and Education, v. 7, p. 95-107, 2009.

ROUSSEAU, J.J. O contrato social: princípios de direito político. Rio de Janeiro: Ediouro, 1993.

SPIVAK, G. Can the Subaltern Speak? Nelson, C. \& Grossberg, L. (eds.) Marxism and the Interpretation of Culture. Urbana, IL: University of Illinois Press, 1988, p. 271313. 